\title{
Metastatic Risk Profile of Microscopic Lymphatic and Venous Invasion in Medullary Thyroid Cancer
}

Authors

Andreas Machens $^{1}{ }^{(D)}$, Kerstin Lorenz ${ }^{1}$, Frank Weber ${ }^{2}$, Henning Dralle ${ }^{1,2}$

Affiliations

1 Department of Visceral, Vascular and Endocrine Surgery, Martin Luther University Halle-Wittenberg, Halle (Saale), Germany

2 Department of General, Visceral and Transplantation Surgery, University of Duisburg-Essen, Essen, Germany

Key words

medullary thyroid carcinoma, lymphatic invasion, venous invasion, lymph node metastases, distant metastases

received 10.04.2021

accepted after revision $\quad 20.07 .2021$

Bibliography

Horm Metab Res 2021; 53: 588-593

DOI 10.1055/a-1559-3424

ISSN 0018-5043

(c) 2021. Thieme. All rights reserved.

Georg Thieme Verlag, Rüdigerstraße 14,

70469 Stuttgart, Germany

Correspondence

Andreas Machens MD

Department of Visceral,

Vascular and Endocrine Surgery

Martin Luther University Halle-Wittenberg

Ernst-Grube-Straße 40

06097 Halle (Saale)

Germany

Tel.: +49345 5572314

AndreasMachens@aol.com
ABSTRACT

The metastatic risk profile of microscopic lymphatic and venous invasion in medullary thyroid cancer is ill-defined. This evidence gap calls for evaluation of the suitability of microscopic lymphatic and venous invasion at thyroidectomy for prediction of lymph node and distant metastases in medullary thyroid cancer. In this study of 484 patients with medullary thyroid cancer who had $\geq 5$ lymph nodes removed at initial thyroidectomy, microscopic lymphatic and venous invasion were significantly associated with greater primary tumor size (27.6 vs. $14.5 \mathrm{~mm}$, and 30.8 vs. $16.2 \mathrm{~mm}$ ) and more frequent lymph node metastasis ( 97.0 vs. $25.9 \%$, and 85.2 vs. $39.5 \%$ ) and distant metastasis ( 25.0 vs. $5.1 \%$, and 32.8 vs. $7.3 \%$ ). Prediction of lymph node metastases by microscopic lymphatic invasion was better than prediction of distant metastases by microscopic venous invasion regarding sensitivity ( 97.0 vs. $32.8 \%$ ) and positive predictive value (58.4 vs. $39.2 \%$ ); comparable regarding negative predictive value ( 98.5 vs. $90.5 \%$ ) and accuracy ( 80.4 vs. $85.1 \%$ ); and worse regarding specificity (74.1 vs. $92.7 \%$ ). On multivariable logistic regression, microscopic lymphatic invasion predicted lymph node metastasis better (odds ratio [OR] 65.6) than primary tumor size (OR 4.6 for tumors $>40 \mathrm{~mm}$ and OR 2.7 for tumors $21-40 \mathrm{~mm}$, relative to tumors $\leq 20 \mathrm{~mm}$ ), whereas primary tumor size was better in predicting distant metastasis (OR 8.3 for tumors $>40 \mathrm{~mm}$ and OR 3.9 for tumors $21-40 \mathrm{~mm}$, relative to tumors $\leq 20 \mathrm{~mm}$ ) than microscopic venous invasion (OR 3.2). These data show that lymphatic invasion predicts lymph node metastases better in medullary thyroid cancer than venous invasion heralds distant metastases.

\section{Introduction}

Microscopic lymphatic vessel invasion in cancer is believed to predict lymph node metastasis, whereas microscopic blood vessel invasion is thought to herald distant metastasis. Although the clinical relevance of vascular invasion as a diagnostic marker of malignancy is widely recognized for follicular thyroid lesions, several reports have suggested that microscopic vascular invasion does not necessarily portend a bad prognosis in differentiated thyroid cancer [1].

For medullary thyroid cancer (MTC), the metastatic risk profile of microscopic lymphatic and venous invasion is ill-defined. MTC has a propensity for early lymph node metastases and distant metastases [2]. Recent research found that hereditary and sporadic MTC do not differ in metastatic behavior [3]. These tumor-specific features make MTC a perfect model to correlate microscopic lymphatic and venous invasion with lymph node and distant metastases.

Microscopic lymphatic and venous invasion, designated L1 and V1 in successive versions of the AJCC/TNM classification of tumors, have been routinely documented in pathology reports at the authors' institution ever since. The present investigation was undertaken to evaluate the suitability of microscopic lymphatic and venous invasion at thyroidectomy for prediction of lymph node and distant metastases in MTC. 


\section{Patients and Methods}

\section{Study population}

Included in this retrospective study were all patients with MTC who underwent initial thyroidectomy with removal of $\geq 5$ lymph nodes between November 1994 and March 2021 at the authors' institution, a tertiary surgical center dedicated to thyroid cancer. All operations were conducted using optical magnification and bipolar coagulation, as described elsewhere [4]. Informed consent was obtained before each operation, which represented standard practice of care at the time in accordance with the practice guidelines of the German Association of Endocrine Surgery [5].

Systematic lymph node dissection was carried out on clinical suspicion by ultrasonography, typically on evidence of enlarged nodes, or confirmation of nodal disease during clinical work-up or intraoperatively. Distant metastases were diagnosed, in the absence of histopathological confirmation, when there was unequivocal evidence on ultrasonography, computed tomography, magnetic resonance imaging, 18-fluorodeoxyglucose or 18-fluorodopamine positron emission, or any combination of these imaging modalities, regardless of when it was noted. The rationale behind this approach was the notion that all lymphatic and hematogenous cancer cell dissemination had already taken place at the time of thyroidectomy, as implies the concept of metastatic dormancy [6].

For retrospective analysis of existing data sets from routine patient care, national law and applicable institutional regulations do not require institutional review board approval.

\section{Histopathological examination}

Conventional staining (hematoxylin and eosin) and calcitonin immunohistochemistry were performed on every surgical specimen. A diagnosis of MTC was based on histopathological evidence of extension beyond the basement membrane according to the criteria defined by the World Health Organization [7]. Primary tumor diameter was ascertained by direct measurements on the surgical thyroid specimens. Thyroid tumors were considered multifocal if two or more foci were found in one or both lobes. When more than one primary thyroid cancer was present, only the largest primary tumor diameter was taken. Microscopic lymphatic and venous invasion was diagnosed when tumor cells resided inside the lumen of one or more lymphatic and venous vessels, respectively. All lymph node metastases were diagnosed on histopathological examination using conventional methodology.

\section{Statistical analysis}

For statistical analysis, the software package SPSS version 25 (IBM, Armonk, New York, USA) was used.

Sensitivity, specificity, and positive and negative predictive values for microscopic lymphatic and venous invasion to predict lymph node and distant metastases were calculated as follows: Sensitivity equals all true-positive findings (metastases) divided by the sum of true-positive and false-negative results regarding microscopic invasion. Specificity equals all true-negative findings (absence of metastases) divided by the sum of true-negative and false-positive results. The positive predictive value equals true-positive results (metastases) divided by the sum of true-positive and false-positive results. The negative predictive value (absence of metastases) equals true-negative results (absence of metastases) divided by the sum of true-negative and false-negative results. Accuracy, representing an overall measure of test performance, equals the sum of true-positive and true-negative results divided by the total number of results.

Categorical data are given as absolute and relative frequencies and were tested with the Fisher's exact test. Continuous data are presented as means with $95 \%$ confidence intervals and range and were compared with the analysis of variance (ANOVA). Multiple testing was adjusted for with the Bonferroni correction [8].

Multivariable logistic regression models were built for MTC to quantify the independent contributions of microscopic lymphatic and venous invasion, primary tumor size, and sex on lymph node and distant metastases. To yield clinically meaningful measures of effect (odds ratios), primary tumor size was categorized in bands of $\leq 20,21-40$, and $>40 \mathrm{~mm}$.

The level of statistical significance (all values were two-tailed) was set at $p<0.05$.

\section{Results}

\section{Baseline characteristics of the study population}

Included in the study were 484 patients with MTC, of whom 345 had sporadic and 139 hereditary diseases. The baseline characteristics of the study population, stratified by the four combinations of microscopic lymphatic and venous invasion, are detailed in - Table 1.

Patients who had neither microscopic lymphatic nor microscopic venous invasion (LOV0) had smaller primary tumors $(13.4 \mathrm{~mm}$ vs. 26.1-31.4 mm) and less frequently lymph node metastases (23 vs. 65-97\%) and distant metastases at thyroidectomy (3 vs. 17-29\%) and at last follow-up (4 vs. 20-37\%).

\section{Comparative analysis of microscopic lymphatic versus venous invasion}

Patients with microscopic lymphatic invasion had more often microscopic venous invasion ( 28.8 vs. $6.5 \%$ ), male sex (63.6 vs. $39.5 \%$ ), larger primary tumors ( 27.6 vs. $14.5 \mathrm{~mm}$ ), lymph node metastases (97.0 vs. $25.9 \%$ ), and distant metastases ( 25.0 vs. $5.1 \%$ ) after correction for multiple testing than patients without ( $\triangleright$ Table 2 , left upper panel).

Patients with microscopic venous invasion had more frequently microscopic lymphatic invasion (60.3 vs. $22.2 \%$ ), larger primary tumors (30.8 vs. $16.2 \mathrm{~mm}$ ), lymph node metastases (85.2 vs. $39.5 \%$ ), and distant metastases (32.8 vs. $7.3 \%$ ) after correction for multiple testing than patients without ( $\triangleright$ Table 2 , right upper panel).

Prediction of lymph node metastases by microscopic lymphatic invasion was better than prediction of distant metastases by microscopic venous invasion regarding sensitivity ( 97.0 vs. $32.8 \%$ ) and positive predictive value (58.4 vs. $39.2 \%$ ); comparable regarding negative predictive value ( 98.5 vs. $90.5 \%$ ) and accuracy $(80.4$ vs. $85.1 \%$ ); and worse regarding specificity (74.1 vs. $92.7 \%$ ) ( $\triangleright$ Table 2, lower panel). 


\section{Multivariable logistic regression analysis on lymph node and distant metastases}

Multivariable logistic regression models were fitted separately on lymph node metastasis and distant metastasis, including all variables that were significant on univariable analysis ( $>$ Table 3 ).

Microscopic lymphatic invasion predicted lymph node metastasis better (odds ratio [OR] 65.6) than primary tumor size (OR 4.6 for tumors $>40 \mathrm{~mm}$ and OR 2.7 for tumors $21-40 \mathrm{~mm}$, relative to tumors $\leq 20 \mathrm{~mm}$ ), whereas the independent contribution of sex was limited (OR 2.2).

Conversely, primary tumor size predicted distant metastasis better (OR 8.3 for tumors $>40 \mathrm{~mm}$ and $O R 3.9$ for tumors $21-40 \mathrm{~mm}$, relative to tumors $\leq 20 \mathrm{~mm}$ ) than microscopic venous invasion (OR 3.2).

\section{Discussion}

This is the first comprehensive study in a real life setting to evaluate the relationship between microscopic lymphatic and venous invasion and lymph node and distant metastases in MTC. Interestingly, prediction of lymph node metastases by microscopic lymphatic invasion was better than prediction of distant metastases by microscopic venous invasion regarding sensitivity and positive predictive value, worse regarding specificity, and comparable regarding negative predictive value and accuracy.

Sensitivity and specificity reflect the intrinsic performance or discriminatory power of a test (presence of microscopic lymphatic and venous invasion), independent of the frequency of the event of interest (lymph node and distant metastases). For infrequent out-

- Table 1 Baseline characteristics of the study population ${ }^{\dagger}$

\begin{tabular}{|c|c|c|c|c|c|}
\hline & Total & Lovo & L1vo & Lov1 & L1V1 \\
\hline No. of patients & $484(100)$ & $329(68.0)$ & $94(19.4)$ & $23(4.8)$ & $38(7.9)$ \\
\hline Age at thyroidectomy (years), mean $[95 \% \mathrm{Cl}]$ & $49.4[47.7 ; 51.0]$ & $49.0[47.0 ; 51.1]$ & $48.4[44.8 ; 52.0]$ & $52.9[47.8 ; 58.0]$ & $52.3[46.9 ; 57.8]$ \\
\hline Sex, no. of male patients & $223(46.1)$ & $129(39)$ & $58(62)$ & $10(44)$ & $26(68)$ \\
\hline $\begin{array}{l}\text { Largest primary tumor size }{ }^{\dagger}(\mathrm{mm}), \text { mean } \\
{[95 \% \mathrm{Cl}]}\end{array}$ & $\begin{array}{l}18.0[16.4 ; 19.6] \\
(n=472)\end{array}$ & $\begin{array}{l}13.4[12.1 ; 14.7] \\
(n=323)\end{array}$ & $\begin{array}{l}26.1[21.6 ; 30.6] \\
(n=90)\end{array}$ & $\begin{array}{l}29.7[18.3 ; 41.2] \\
(n=23)\end{array}$ & $\begin{array}{l}31.4[24.5 ; 38.4] \\
(n=36)\end{array}$ \\
\hline No. of patients with multifocal tumor growth & $123(25.4)$ & $81(25)$ & $32(34)$ & $1(4)$ & $9(24)$ \\
\hline No. of patients with lymph node metastases & $219(45.2)$ & $76(23)$ & $91(97)$ & $15(65)$ & $37(97)$ \\
\hline $\begin{array}{l}\text { No. of patients with distant metastases at } \\
\text { thyroidectomy }\end{array}$ & $40(8.3)$ & $9(3)$ & $16(17)$ & $4(17)$ & $11(29)$ \\
\hline $\begin{array}{l}\text { No. of patients with distant metastases at } \\
\text { last follow-up }\end{array}$ & $51(10.5)$ & $12(4)$ & $19(20)$ & $6(26)$ & $14(37)$ \\
\hline \multicolumn{6}{|l|}{ No. of patients with } \\
\hline lung metastases at last follow-up & $32(6.6)$ & $6(2)$ & $13(14)$ & $3(13)$ & $10(26)$ \\
\hline bone metastases at last follow-up & $22(4.5)$ & $6(2)$ & $11(12)$ & $2(9)$ & $3(8)$ \\
\hline liver metastases at last follow-up & $27(5.6)$ & $6(2)$ & $11(12)$ & $4(17)$ & $6(16)$ \\
\hline brain metastases at last follow-up & $2(0.4)$ & 0 & $1(1)$ & 0 & $1(3)$ \\
\hline \multicolumn{6}{|l|}{ No. of patients with lymph node dissection } \\
\hline central & $479(99.0)$ & 326 (99) & $94(100)$ & $22(96)$ & $37(97)$ \\
\hline ipsilateral lateral & $408(84.3)$ & $259(79)$ & $91(97)$ & $22(96)$ & $36(95)$ \\
\hline contralateral lateral & $345(71.3)$ & $225(68)$ & $73(78)$ & $18(78)$ & $29(76)$ \\
\hline $\begin{array}{l}\text { No. of patients with microscopic lymphatic } \\
\text { invasion (L1) }\end{array}$ & $132(27.3)$ & & & & \\
\hline $\begin{array}{l}\text { No. of patients with microscopic venous } \\
\text { invasion (V1) }\end{array}$ & $61(12.6)$ & & & & \\
\hline $\begin{array}{l}\text { No. of patients who had increased } \\
\text { preoperative calcitonin levels } \geq 10 \mathrm{pg} / \mathrm{ml} \\
\text { and were biochemically cured }\end{array}$ & $\begin{array}{l}288(66.5) \\
(n=433)\end{array}$ & & & & \\
\hline Follow-up (months), mean [95\% Cl] & $\begin{array}{l}55.5[48.4 ; 62.6] \\
(\mathrm{n}=245)\end{array}$ & & & & \\
\hline
\end{tabular}


- Table 2 Comparative analysis of medullary thyroid cancer: microscopic lymphatic versus venous invasion.

\begin{tabular}{|c|c|c|c|c|c|c|}
\hline & \multicolumn{2}{|c|}{ Microscopic lymphatic invasion } & \multirow[t]{2}{*}{$\mathbf{p}$} & \multicolumn{2}{|c|}{ Microscopic venous invasion } & \multirow[t]{2}{*}{$\mathbf{p}$} \\
\hline & Present (L1) & Absent (L0) & & Present (V1) & Absent (V0) & \\
\hline No. of patients & $132(27.3)$ & $352(72.7)$ & & $61(12.6)$ & $423(87.4)$ & \\
\hline $\begin{array}{l}\text { No. of patients } \\
\text { with microscopic } \\
\text { venous invasion }\end{array}$ & $38(28.8)$ & $23(6.5)$ & $<0.001^{*}$ & & & \\
\hline $\begin{array}{l}\text { No. of patients } \\
\text { with microscopic } \\
\text { lymphatic } \\
\text { invasion }\end{array}$ & & & & $38(60.3)$ & $94(22.2)$ & $<0.001^{*}$ \\
\hline $\begin{array}{l}\text { Age at thyroidec- } \\
\text { tomy (years) } \\
\text { mean }[95 \% \mathrm{Cl}]\end{array}$ & $49.5[46.5 ; 52.5]$ & $49.3[47.3 ; 51.3]$ & 0.903 & $52.9[48.7 ; 56.4]$ & $48.9[47.1 ; 50.7]$ & 0.144 \\
\hline $\begin{array}{l}\text { Sex, no. of male } \\
\text { patients }\end{array}$ & $84(63.6)$ & $139(39.5)$ & $<0.001^{*}$ & $36(59.0)$ & $187(44.2)$ & 0.039 \\
\hline $\begin{array}{l}\text { Largest primary } \\
\text { tumor size }(\mathrm{mm}) \\
\text { mean }[95 \% \mathrm{Cl}]\end{array}$ & $\begin{array}{l}27.6[23.8 ; 31.4] \\
(n=126)\end{array}$ & $\begin{array}{l}14.5[13.0 ; 16.0] \\
(n=346)\end{array}$ & $<0.001^{*}$ & $\begin{array}{l}30.8[24.8 ; 36.7] \\
(n=59)\end{array}$ & $\begin{array}{l}16.2[14.7 ; 17.7] \\
(n=413)\end{array}$ & $<0.001^{*}$ \\
\hline $\begin{array}{l}\text { No. of patients } \\
\text { with multifocal } \\
\text { tumor growth }\end{array}$ & $41(31.1)$ & $82(23.4)$ & 0.101 & $10(16.4)$ & $113(26.8)$ & 0.086 \\
\hline $\begin{array}{l}\text { No. of patients } \\
\text { with lymph node } \\
\text { metastases }\end{array}$ & $128(97.0)$ & $91(25.9)$ & $<0.001^{*}$ & $52(85.2)$ & $167(39.5)$ & $<0.001^{*}$ \\
\hline $\begin{array}{l}\text { No. of patients } \\
\text { with distant } \\
\text { metastases at last } \\
\text { follow-up }\end{array}$ & $33(25.0)$ & $18(5.1)$ & $<0.001^{*}$ & $20(32.8)$ & $31(7.3)$ & $<0.001^{*}$ \\
\hline Sensitivity (\%) & 97.0 & & & 32.8 & & \\
\hline Specificity (\%) & 74.1 & & & 92.7 & & \\
\hline $\begin{array}{l}\text { Positive } \\
\text { predictive value } \\
\text { (\%) }\end{array}$ & 58.4 & & & 39.2 & & \\
\hline $\begin{array}{l}\text { Negative } \\
\text { predictive value } \\
\text { (\%) }\end{array}$ & 98.5 & & & 90.5 & & \\
\hline Accuracy (\%) & 80.4 & & & 85.1 & & \\
\hline
\end{tabular}

comes, negative predictive values are bound to be high $(98.5 \%$ for microscopic lymphatic invasion and $90.5 \%$ for microscopic venous invasion), whereas positive predictive values typically are lower (58.4\% for microscopic lymphatic invasion and 39.2\% for microscopic venous invasion) depending on the event rate ( $45.2 \%$ for lymph node metastases, and $10.5 \%$ for distant metastases; $>$ Table $\mathbf{1})$.

In clinical practice, though, the number of lymph node metastases, in particular when exceeding 20 , may be better suited practice to herald distant metastases [9] and portend worse clinical outcome $[10,11]$.
Arguably, lymphatic tumor cell dissemination may lead more easily to implantation and growth in mesenchymal organs (lymph node metastases) than venous tumor cell dissemination to implantation and growth in other parenchymal organs (distant metastases). Detection of lymph node metastases removed during compartment-oriented surgery, however, is more comprehensive than detection of distant metastases, which relies on imaging and longterm clinical follow-up. Indeed, the present study required five or more harvested lymph nodes for inclusion to ensure that a repre- 
- Table 3 Multivariable logistic regression analysis on lymph node and distant metastases.

\begin{tabular}{|c|c|c|c|c|c|c|}
\hline \multirow[b]{2}{*}{ Independent variable } & & \multirow[b]{2}{*}{ Patients } & \multicolumn{2}{|c|}{ Lymph node metastasis $^{\dagger}$} & \multicolumn{2}{|l|}{ Distant metastasis $\ddagger^{\ddagger^{*}}$} \\
\hline & & & Odds ratio $[95 \% \mathrm{Cl}]$ & $\mathbf{p}$ & Odds ratio $[95 \% \mathrm{Cl}]$ & $\mathbf{p}$ \\
\hline $\begin{array}{l}\text { Microscopic lymphatic } \\
\text { invasion }\end{array}$ & $\begin{array}{l}\text { present vs. } \\
\text { absent }\end{array}$ & 126 vs. 346 & $65.6[23.1 ; 186.1]$ & $<0.001$ & $2.2[1.1 ; 4.6]$ & 0.033 \\
\hline $\begin{array}{l}\text { Microscopic venous } \\
\text { invasion }\end{array}$ & $\begin{array}{l}\text { present vs. } \\
\text { absent }\end{array}$ & 59 vs. 413 & $4.8[1.9 ; 12.2]$ & $<0.001$ & $3.2[1.5 ; 6.9]$ & 0.002 \\
\hline \multirow{3}{*}{$\begin{array}{l}\text { Largest primary tumor } \\
\text { size, mm }\end{array}$} & $>40$ & 41 & $4.6[1.6 ; 13.0]$ & 0.004 & $8.3[3.3 ; 20.9]$ & $<0.001$ \\
\hline & $21-40$ & 103 & $2.7[1.5 ; 5.0]$ & 0.001 & $3.9[1.7 ; 8.7]$ & 0.001 \\
\hline & $\leq 20$ & 328 & 1 & & 1 & \\
\hline Sex & male vs. female & 214 vs. 258 & $2.2[1.3 ; 3.6]$ & 0.003 & $1.1[0.6 ; 2.2]$ & 0.765 \\
\hline
\end{tabular}

Cl: Confidence interval. * At last follow-up. ${ }^{2} 208$ metastatic events (44.1\%) in 472 patients with information on primary tumor size. $\ddagger 45$ metastatic events $(9.5 \%)$ in 472 patients with information on primary tumor size.

sentative number of lymph nodes had been submitted to histopathological examination.

Tumor cells invading blood vessels prompt formation of platelet-tumor aggregates. Tumor thrombi are thought to be critical for survival of tumor cells in the blood system and implantation of distant metastases [1]. Applying more rigid criteria, including evidence of tumor cells penetrating a vessel wall and thrombus adherent to intravascular tumor, Mete and Asa decreased the percentage of angioinvasive differentiated thyroid cancers to $3 \%$, of which one-third gave rise to distant metastases. In good keeping, $32.8 \%$ of patients with angioinvasive MTC developed distant metastases in this study ( $\triangleright$ Table 2). The diagnosis of lymphatic and venous invasion cannot be standardized completely, leaving some element of subjectivity (intra-observer and inter-observer variability). Of note, non-differential variability works to level, not to augment, more subtle histopathological differences.

Owing to the need for sufficient tissue to construct a tissue microarray, overrepresentation of advanced thyroid cancers in pathological series is not uncommon. For instance, the rates of lymphatic invasion, angioinvasion, and distant metastasis were 2-3 times greater in a pathological series of $\operatorname{MTC}(70,43$, and $26 \%)$ [12] than in the present real-life setting $(27.3,12.6$, and $10.5 \%$; Table 1$)$. In that enriched pathological series, mean patient age was 72 years. and mean tumor size was $27 \mathrm{~mm}$ [12], as compared to 49.4 years and $18.0 \mathrm{~mm}$ ( $\triangleright$ Table 1 ) in the present investigation.

This clinical-histopathological investigation was not designed to estimate time to distant metastasis, which is notoriously difficult to measure. Many patients were referred for thyroidectomy from afar, and followed up at outside facilities, so that the clinical workup was not standardized as to frequency and type of imaging. Conceptually, the actual lifetime risk of lung, bone, liver, and brain metastases may be even greater if the observation period was extended and endoscopic procedures (thoracoscopy and laparoscopy), invasive imaging (arterial hepatic angiography), and advanced ima- ging technologies had been used more liberally than is current medical practice.

\section{Conclusions}

Microscopic lymphatic invasion predicted lymph node metastases better in MTC than microscopic venous invasion heralded distant metastases. These real-life data strongly support separation of lymphatic from vascular invasion in MTC. Intriguingly, Mete and Asa found that all their patients with angioinvasive differentiated thyroid cancer and distant metastases revealed predominantly a single focus of angioinvasion, and that there were no more than two foci of vascular invasion [1]. Based on this observation, the use of appropriate histopathological criteria may be more critical than the number of involved vessels. Remarkably, not only absence of lymphatic invasion, but even more so absence of desmoplastic stroma may herald absence of lymph node metastases [13, 14]. Further research is warranted to optimize clinical follow-up and explore the role of adjuvant therapy in patients with angioinvasive MTC using stringent histopathological criteria.

\section{Conflict of Interest}

The authors declare that they have no conflict of interest.

\section{References}

[1] Mete O, Asa SL. Pathological definition and clinical significance of vascular invasion in thyroid carcinomas of follicular epithelial derivation. Mod Pathol 2011; 24: 1545-1552 
[2] Hugen N, Sloot YJE, Netea-Maier RT et al. Divergent metastatic patterns between subtypes of thyroid carcinoma results from the nationwide Dutch pathology registry. J Clin Endocrinol Metab 2020; 105: e299-e306

[3] Machens A, Lorenz K, Weber F et al. Exceptionality of distant metastases in node-negative hereditary and sporadic medullary thyroid cancer: Lessons learned. J Clin Endocrinol Metab 2021; 106: e2968-e2979

[4] Dralle H. Lymph node dissection and medullary thyroid carcinoma. $\mathrm{Br}$ ] Surg 2002; 89: 1073-1075

[5] Dralle H, Musholt T], Schabram J et al. German Association of Endocrine Surgeons practice guideline for the surgical management of malignant thyroid tumors. Langenbecks Arch Surg 2013; 398: 347-375

[6] Rajan N, Khanal T, Ringel MD. Progression and dormancy in metastatic thyroid cancer: concepts and clinical implications. Endocrine 2020; 70: 24-35

[7] DeLellis RA, Lloyd RV, Heitz PU et al. Pathology and genetics of tumours of endocrine organs; In: WHO classification of tumours of endocrine organs. World Health Organisation Classification; 3rd edition, 2017
[8] Bland JM, Altman DG. Multiple significance tests: The Bonferroni method. BMJ 1995; 310: 170

[9] Machens A, Dralle H. Prognostic impact of N staging in 715 medullary thyroid cancer patients: Proposal for a revised staging system. Ann Surg 2013; 257: 323-329

[10] Esfandiari NH, Hughes DT, Yin $\mathrm{H}$ et al. The effect of extent of surgery and number of lymph node metastases on overall survival in patients with medullary thyroid cancer. J Clin Endocrinol Metab 2014; 99: 448-454

[11] Moses LE, Oliver JR, Rotsides JM et al. Nodal disease burden and outcome of medullary thyroid carcinoma. Head Neck 2021; 43: 577-584

[12] Erovic BM, Kim D, Cassol C et al. Prognostic and predictive markers in medullary thyroid carcinoma. Endocr Pathol 2012; 23: 232-242

[13] Aubert S, Berdelou A, Gnemmi V et al. Large sporadic thyroid medullary carcinomas: Predictive factors for lymph node involvement. Virchows Arch 2018; 472: 461-468

[14] Niederle MB, Riss P, Selberherr A et al. Omission of lateral lymph node dissection in medullary thyroid cancer without a desmoplastic stromal reaction. Br J Surg 2021; 108: 174-181 